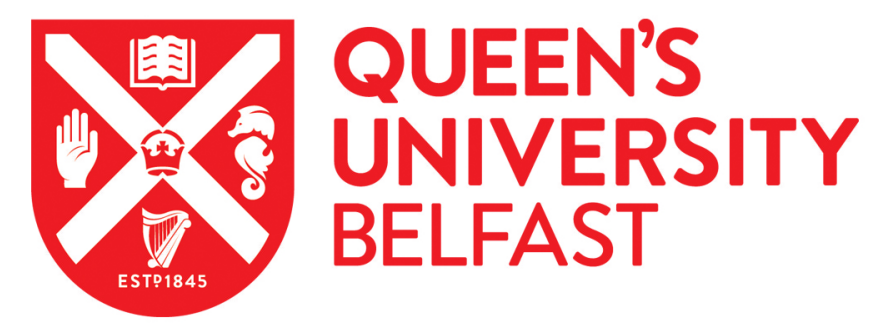

\title{
Preliminary Evaluation of the Values Tracker
}

Pielech, M., Bailey, R. W., McEntee, M. L., Ashworth, J., Levell, J., Sowden, G., \& Vowles, K. E. (2016).

Preliminary Evaluation of the Values Tracker: A Two-Item Measure of Engagement in Valued Activities in Those With Chronic Pain. Behavior Modification, 4O(1-2), 239-256. https://doi.org/10.1177/0145445515616911

Published in:

Behavior Modification

Document Version:

Peer reviewed version

Queen's University Belfast - Research Portal:

Link to publication record in Queen's University Belfast Research Portal

Publisher rights

Copyright 2016 SAGE. This work is made available online in accordance with the publisher's policies. Please refer to any applicable terms of use of the publisher.

\section{General rights}

Copyright for the publications made accessible via the Queen's University Belfast Research Portal is retained by the author(s) and / or other copyright owners and it is a condition of accessing these publications that users recognise and abide by the legal requirements associated with these rights.

Take down policy

The Research Portal is Queen's institutional repository that provides access to Queen's research output. Every effort has been made to ensure that content in the Research Portal does not infringe any person's rights, or applicable UK laws. If you discover content in the Research Portal that you believe breaches copyright or violates any law, please contact openaccess@qub.ac.uk. 
Running head: Preliminary evaluation of the Values Tracker

\section{Preliminary Evaluation of the Values Tracker:}

A Two-Item Measure of Engagement in Valued Activities in Chronic Pain

Melissa Pielech ${ }^{1}$, Robert W. Bailey ${ }^{1}$, Mindy L. McEntee ${ }^{1}$, Julie Ashworth ${ }^{2}$, Jayne Levell ${ }^{2}$, Gail Sowden $^{2}, \&$ Kevin E. Vowles ${ }^{1}$

${ }^{1}$ Department of Psychology, University of New Mexico, Albuquerque, USA

${ }^{2}$ IMPACT Pain Service, Haywood Hospital, Staffordshire \& Stoke on Trent Partnership NHS Trust, Stoke on Trent, UK

Correspondence to: Melissa Pielech or Kevin Vowles

Address: University of New Mexico, Department of Psychology

MSC03 2220 | Logan Hall

1 University of New Mexico

Albuquerque, NM 87131

Email: melissapielech@gmail.com or k.e.vowles@gmail.com

Phone: 401.419.2361

Fax: 505.277.1394

Total pages: 25

Tables: 2 


\section{Author Biographical Statements}

Melissa Pielech has an MA in Mental Health Counseling and Art Therapy and is currently pursuing a PhD in Clinical Psychology at the University of New Mexico. She is specifically interested in ACT-based chronic pain rehabilitation and assessment of psychosocial functioning in caregivers of pediatric patients with chronic pain.

Robert W. Bailey received his MA in psychology from Adelphi University and is currently working toward a PhD in clinical psychology at the University of New Mexico. His areas of professional interest include behavioral medicine, mindfulness-based interventions, such as acceptance and commitment therapy, and quantitative methodology.

Mindy L. McEntee is pursuing a PhD in clinical psychology at the University of New Mexico with an emphasis in health psychology and quantitative methodology. Her clinical and research interests include health behavior change interventions and assessment in populations with chronic conditions, particularly obesity and diabetes.

Julie Ashworth is a Consultant in Anaesthesia \& Pain Medicineat the University Hospitals of North Midlands and IMPACT Chronic Pain Service. She is a Fellow of the Royal College of Anaesthetists and faculty of Pain Medicine and an Honorary Senior Lecturer at Keele University. She has longstanding interests in the effective treatment of chronic pain.

Jayne Levell is qualified as a Clinical Psychologist in the UK in 2003. She has worked extensively in physical health settings, focusing on the impact of long term conditions and adjustment to them. She is currently a Consultant Clinical Psychologist with the IMPACT Chronic Pain Service, for the Staffordshire and Stoke-on-Trent Partnership NHS Trust.

Gail Sowden is a Consultant Physiotherapist in pain management and vocational rehabilitation, areas where she has significant clinical, research, service development, and academic expertise. She is currently employed by the IMPACT Chronic Pain Service and Keele University.

Kevin E. Vowles received his PhD from West Virginia University and has been working in the field of pain rehabilitation for the majority of his career. He has published over 65 articles in the area since 2002. He is currently an Associate Professor in the Department of Psychology at the University of New Mexico. 


\begin{abstract}
Engagement in valued activities is an important outcome, particularly in treatments that aim to enhance quality of life in those with chronic conditions. The present study describes the initial evaluation of the Values Tracker (VT), a two item measure of values engagement, in 302 treatment seeking adults with chronic pain. Hierarchical regression analyses were conducted to examine the utility of the VT in the statistical prediction of pain-related functioning, after controlling for pain intensity and pain-related distress. Across analyses, pain intensity accounted for significant variance (range $\Delta r^{2}=.06$ - .09) with pain-related distress adding additional unique variance (range $\Delta r^{2}=.07-.19$ ). The VT accounted for additional unique variance (range $\Delta r^{2}=$ $.02-.17)$ for all variables with the exception of physical disability. These findings provide initial support for the utility of the VT in those with chronic pain. Given the VT's brevity, it may be particularly useful for tracking changes in engagement in values across sessions.
\end{abstract}




\section{Introduction}

Chronic pain, often defined as pain lasting longer than three to six months, impacts a significant proportion of adults and is associated with disruptions in daily, vocational, interpersonal, and psychosocial functioning (Breivik, Collett, Ventafridda, Cohen, \& Gallacher, 2006; Gaskin \& Richard, 2012; Smith et al., 2001). Despite centuries of treatments aimed at controlling, reducing, or eliminating pain (e.g. analgesic medications, injections, surgical procedures) studies reveal that the majority of pain sufferers experience pain long-term (Andersson, 2004; Breivik, Campbell, \& Nicholas, 2008; Elliott, Smith, Hannaford, Smith, \& Chambers, 2002). Thus, psychosocial approaches to treating chronic pain have historically prioritized decreasing disability and increasing activity engagement, with more recent approaches providing a distinctive focus on empowering patients with the means to live a meaningful life with ongoing pain (e.g., Fordyce, 1976; Main, Keefe, Vlaeyen, \& Vowles, 2014; L M McCracken, 2005; McCracken \& Vowles, 2014).

Acceptance and Commitment Therapy (ACT; Hayes, Strosahl, \& Wilson, 2012), an intervention considered by the American Psychological Association's (APA) Division of Clinical Psychology (APA, 2013) to have "strong" empirical support for treatment of chronic pain, is founded on the aforementioned principles. Specifically, the primary aim of ACT is to enable pain sufferers to build a repertoire of flexible patterns of values-directed behavior, even when in persistent contact with pain and discomfort. ACT suggests that pain reduction is not a necessary pre-requisite to living a valued life or decreasing disability (McCracken \& Vowles, 2014; Vowles \& Thompson, 2011). This approach can be particularly helpful for patients who have struggled with unsuccessful attempts for pain control and/or relief in the past or have 
experienced greater difficulty as a result of these attempts (McCracken \& Vowles, 2014; McCracken, 2005; Vowles \& Thompson, 2011)

Another key objective of ACT is to facilitate patient engagement in valued activities, defined specifically as activities that contribute to improved quality of life, vitality, or meaning (Hayes et al., 2012). Within an ACT framework, values are used as the basis for guiding behavioral change, and thus, movement towards values-directed behavior is an important marker of treatment success in ACT. Previous research has found associations between successful valuesdirected living and measures of disability, depression, and pain-related anxiety (Jensen, Vowles, Johnson, \& Gertz, in press.; McCracken \& Vowles, 2008; McCracken \& Yang, 2006) and improvements in valued engagement over the course of treatment are predictive of improvements in these same measures of patient functioning through follow-ups of as long as three years (Vowles, McCracken, \& O’Brien, 2011; Vowles \& McCracken, 2008; Vowles, Witkiewitz, Sowden, \& Ashworth, 2014).

While there are measures of engagement in valued activities for use with those with chronic pain (Jensen et al., in press; McCracken \& Yang, 2006), their length can imped feasibility to be used frequently and repeatedly. Thus, there is a space to develop an assessment of engagement in valued activity that is brief enough to be administered multiple times over the course of treatment. This would allow clinicians and researchers to track development over time, identify a lack of improvement, and evaluate how trajectories of change relate to longer term improvements in important areas of patient physical and emotional functioning. Additionally, development of a brief measure that is sensitive to session-by-session changes (e.g. weekly or daily) will help to identify and understand patterns of behavior change related to values 
engagement over the course of a treatment intervention and, in turn, how changes in engagement in valued activity relate to levels of functioning.

This study details the initial cross sectional evaluation of a two-item measure of engagement in valued activities, termed the Values Tracker (VT), within a sample of treatment seeking adults with chronic pain. The primary aim was to determine the utility of the VT in the statistical prediction of various aspects of pain-related functioning. Measures of physical and emotional performance included disability, depression, and pain-related anxiety. In addition, in order to evaluate the convergent validity of the VT items, measures assessing constructs relevant to ACT, including pain acceptance, valued activity (including both values success and the discrepancy between rated importance and success in valued domains), and self-compassion were also included. Finally, pain coping behaviors, including more traditional coping behaviors and those related to ACT approaches, were evaluated. Hierarchical regression analyses, controlling for pain intensity and pain-related distress, were conducted to examine the statistical contribution of the VT items to these measures of patient functioning. While a cross-sectional analysis does not allow for an evaluation of the utility of the VT over time, a cross sectional approach is a necessary first step in order to validate the measure and evaluate the relations between valuesbased action and patient functioning in the context of chronic pain.

\section{Procedure}

\section{Methods}

All measures were completed as part of an initial assessment appointment at a specialty pain service located in the midlands of the UK. All participants provided informed consent and the data collection procedures were approved by the regional Human Subject Protection Board of the National Health Service. 


\section{Participants}

In total, data were collected from 302 consecutive patients presenting for a treatment assessment appointment between December 2011 and November 2014. Participants were primarily White European (99.3\%) and female (64.8\%). The majority was married or cohabitating (65.1\%), while others were single (14.4\%), divorced $(13.4 \%)$, or widowed $(7.0 \%)$. Mean age was 54.7 years $(\mathrm{SD}=13.4)$. Mean years of education was $13.4(\mathrm{SD}=3.8)$, and the majority of patients $(68 \%)$ reported completing at least the compulsory course of education.

The most prevalent pain diagnoses were fibromyalgia (26.5\%), arthritis $(20.6 \%)$, degenerative disc disease (8.8\%), sciatica $(8.8 \%)$, and hensiated disk $(7.4 \%)$. With regard to pain location, just under half of participants (46.9\%) reported back pain (e.g. lumbar, spine, sacrum) as the primary site of their pain, while others noted their primary pain location to be lower limbs (23.8\%), full or hemi-body (13.9\%), cervical spine (7.3\%), thoracic spine (4.6\%) and pelvic, head, or upper limb (all $\leq 2.0 \%$ ). Duration of pain varied substantially from three months to 54.7 years, with a median value of 9.3 years. Only $21.5 \%$ of patients reported working outside the home on a full or part-time basis. An additional 1.3\% reported working as a homemaker.

\section{Measures}

Each patient completed a battery of self-report questionnaires assessing aspects of painrelated physical and psychosocial functioning, demographic, and pain-related medical characteristics at one time point. These measures were completed prior to their assessment appointment.

Engagement in Valued Activities. As noted, the Values Tracker (VT) is a two-item measure, adapted from a daily diary that was designed to measure pain intensity, struggles for pain control, and engagement in valued activities in adult patients undergoing Acceptance and 
Commitment therapy (ACT) for chronic pain (Vowles, Fink, \& Cohen, 2014). The two-items in the VT were chosen from the larger diary because of their focus on assessing patient engagement in valued activities and effectiveness in actions, key treatment targets in ACT. Item 1 queries on quality of living asking respondents to, "Rate how effective you were in taking actions that contributed to a better, more vital, quality of living in the past week" (referred to in this analysis as "Vital Actions") while Item 2 states, "Rate how effective you were this past week in making progress in the areas of your life that matter to you" (referred to in this analysis as "Values Progress"), focusing on areas of living that matter most. Items are rated on a scale of 1 (Not at all) to 10 (Most possible). The two items were summed to derive a composite VT score. In the present sample, the two items were significantly correlated $(r=.71, p<.001)$.

Pain Intensity and Pain-related Distress. Participants reported usual intensity of pain in the past week on a scale of 0 (No pain) to 10 (Worst pain possible), and how distressing the pain had been over the past week, also rated on a scale of 0 (Not distressing) to 10 (Extremely distressing). The use of Numerical Rating Scales such as those used here have been widely supported (Campbell \& Vowles, 2008; Jensen \& Karoly, 1992; Vowles, Gross, \& McCracken, 2007).

\section{Pain-related functioning}

Disability. The Sickness Impact Profile (SIP; Bergner, Bobbitt, Carter, \& Gilson, 1981) is comprised of 136 yes or no questions to compute an index of health and health-related dysfunction across three dimensions (physical, psychosocial, and independence-related disability). Total scores range from $0-1$, with higher scores indicating higher levels of healthrelated disability. The SIP is a widely used and supported measure of disability in chronic pain (Vowles, Gross, \& McCracken, 2007). 
Depression. The British Columbia Major Depression Inventory (BCMDI; Iverson \& Remick, 2004) is a measure that assesses for presence and severity of major depression, as defined by the $4^{\text {th }}$ edition of the Diagnostic and Statistical Manual of Mental Disorders (American Psychiatric Association, 2000). Symptom severity is reported across 16 items, which range from 1 (Very mild problem) to 5 (Very severe problem). Items are summed to obtain a total score (range 0-80) with higher scores reflecting higher levels of symptoms. The BCMDI has demonstrated good psychometric properties, as well as excellent sensitivity and specificity for a diagnosis of Major Depression Disorder (Iverson \& Remick, 2004).

Pain-Related Anxiety. The 20-item Pain Anxiety Symptoms Scale (PASS; McCracken \& Dhingra, 2002) was used to evaluate anxiety and avoidance behaviors in the context of pain. The measure has 20 items with response options on a scale from 0 (Never) to 5 (Always). The PASS has demonstrated good reliability, validity, utility, as well as predictive validity in chronic pain populations (McCracken \& Dhingra, 2002; Roelofs et al., 2004; Vowles, Zvolensky, Gross, \& Sperry, 2004)

\section{ACT constructs}

Pain Acceptance. The Chronic Pain Acceptance Questionnaire (CPAQ; McCracken, Vowles, \& Eccleston, 2004) is a 20 item measure of pain-related acceptance. Items are rated on a 7-point Likert-scale ranging from 0 (Never true) to 6 (Always true) and summed to comprise a total score. The factor structure of the CPAQ and its psychometric properties have strong empirical support (Reneman, Dijkstra, Geertzen, \& Dijkstra, 2010; Vowles, McCracken, McLeod, \& Eccleston, 2008; Wicksell, Olsson, \& Melin, 2009).

Values Success and Discrepancy. The Chronic Pain Values Inventory (CPVI; McCracken \& Yang, 2006) is a 12-item measure assessing level of importance and success in patient values 
across six domains, including family, intimate relations, friends, work, health, and growth or learning. A Likert-type scale is used to measure level of importance and the degree to which patient actions have successfully been guided by values. The scales range from 0 (Not at all important/ successful) up to 5 (Extremely important/ successful). Responses are used to calculate values for three subscales: (1) Values Success, (2) Values Importance, and (3) Values Discrepancy between reported levels of values success and importance. In this analysis, the Values Success subscale and the Discrepancy subscales were used as measures of values-based action. The CPVI has previously demonstrated acceptable psychometric characteristics (McCracken \& Yang, 2006).

Self-Compassion. The Self Compassion Scale (SCS; Neff, 2003) is a 26-item measure which assesses level of kindness and understanding toward oneself, particularly in the face of failure, pain, or suffering. The items are rated on a 5-point Likert Scale ranging from 1 (Almost never) to 5 (Almost always). The original validation study demonstrated the psychometric properties of the SCS (Neff, 2003) and it has been successfully utilized in chronic pain samples (Vowles, Sowden, \& Ashworth, 2014; Vowles, Witkiewitz, et al., 2014).

\section{Pain coping behaviors}

Psychological Flexibility and Traditional Pain Management Coping. The Brief Pain Coping Inventory 2 (BPCI-2; McCracken \& Vowles, 2007) is comprised of 19 items that are spread across two subscales: (1) Psychological Flexibility and (2) Traditional Pain Management. The Psychological Flexibility subscale includes coping behavior items related to acceptance of pain and distress, engagement of daily activities while acknowledging presence of pain, and present-focused awareness. The Traditional Pain Management subscale is comprised of coping behavior items related to traditional approaches to pain management such as distraction, 
relaxation, activity pacing. Respondents are asked to report on how many days within the past week they responded to their pain in the way described by the item. Higher scores indicate more frequent engagement in the coping behaviors. Previous work has supported the utility of the BPCI-2 subscales, particularly the Psychological Flexibility subscale (McCracken \& Vowles, 2007; Vowles, McCracken, Sowden, \& Ashworth, 2014; Vowles \& McCracken, 2010).

\section{Statistical Analysis}

All data were entered and analyzed using SPSS, version 23. Following inspection of demographic and descriptive values, bivariate Pearson correlation coefficients were computed to evaluate associations among the VT, pain intensity, pain-related distress, and measures of patient functioning, including disability, depression, pain-related anxiety, pain acceptance, values success, values importance-success discrepancy, self-compassion, and coping behaviors. Next, a series of hierarchical regression analyses were performed to determine if the VT was able to account for additional variance in measures of patient functioning, after controlling for relevant background variables. The first step included gender, age, and pain duration, which were entered in a stepwise fashion so that only statistically relevant variables were included. Next, ratings of pain intensity and pain-related distress were entered in the second and third steps, respectively. Scores on the VT were entered in the final step.

In addition to these primary regression analyses, a supplemental set of analyses were also conducted examining the utility of the VT after controlling for values scores as assessed by the values success and values discrepancy scores of the CPVI. Given that the VT and CPVI both aim to address values-based action, it was felt that a series of regressions which entered CPVI scores as the fourth step, followed by VT scores would be an appropriately stringent test of incremental validity. 


\section{Results}

\section{Descriptive Statistics}

Mean response value for VT items was as follows: $\mathrm{M}=5.2(\mathrm{SD}=2.6)$ for the "Vital Actions" item ("Rate how effective you were in taking actions that contributed to a better, more vital, quality of living in the past week") and $\mathrm{M}=4.6(\mathrm{SD}=2.8)$ for the "Values Progress" item ("Rate how effective you were this past week in making progress in the areas of your life that matter to you"). When the VT items were summed, the full score range of 0 to 20 was evident in the sample with $M=9.7(S D=4.9)$. Average pain intensity score from the past week was 8.5 $(\mathrm{SD}=1.5)$, while mean rating for level of pain-related distress was $6.5(\mathrm{SD}=2.7)$. Mean scores for measures of pain-related functioning are detailed in Table 1.

\section{Relations between the Values Tracker, Pain Variables, and Patient Functioning Variables}

As noted, the VT items were strongly and significantly associated with each other $(r=$ $.71, p<.001$ ). Neither item was significantly correlated with pain intensity (Vital Actions: $r=$ $.07, p=\mathrm{ns}$; Values Progress: $r=-.06, p=\mathrm{ns}$ ). Level of pain-related distress correlated significantly with the Values Progress item $(r=-.18, p<.01)$, but not with the Vital Actions item $(r=-.08, p=n s)$. The VT sum score was not correlated with pain intensity $(\mathrm{r}=-.07, p=.23)$ and was modestly correlated with pain-related distress $(r=-.14, p=.05)$.

Further correlation analysis revealed that the summary score of the VT items had significant associations with all facets of patient functioning (results displayed in Table 1). The strongest associations were present between the VT and measures of pain coping behaviors (psychological flexibility coping, $r=-.44, p<.001$; traditional pain management coping, $r=$ $.34, p<.001$ ), as well as measures of ACT constructs (levels of values success, $r=-.41, p<$ 
.001 ; self-compassion $r=.33, p<.001$; pain acceptance, $r=.32, p<.001)$. The VT was most weakly related to physical disability $(r=-.13, p<.05)$.

Pain intensity and pain-related distress were also highly correlated with measures of functioning (see Table 1). Of note, pain intensity was not significantly associated with values success $(r=-.12, p=.06)$, discrepancy between values importance and success $(r=-.11, p=$ $.09)$, psychological flexibility coping $(r=-.11, p=.20)$, traditional pain management coping, $(r$ $=-.004, p=.96)$, or self-compassion $(r=-.11, p=.19)$. Level of pain-related distress was significantly associated with all measures of patient functioning except for level of using traditional pain management techniques for coping $(r=-.10, p=.23)$.

\section{Hierarchical Regression Analyses}

The results of the regression analyses are displayed in Table 2. Tolerance values of .69 to .99 and variance inflation factors of 1.01 to 1.45 met the recommended cutoffs and suggest multicollinearity was not problematic in these analyses (Cohen, Cohen, West, \& Aiken, 2003).

Results indicated that the background variables of age and gender did not account for significant variance in any of the regression analyses. Pain duration was significant for only two of 11 regressions, which included physical disability and pain-related fear $\left(\Delta R^{2}=.02, p<.05\right.$ in each case). Significant final model beta-weights were indicated in each case.

In the second step of the regressions, pain intensity accounted for significant variance for six of the eleven measures (physical, psychosocial, and independence/other disability, depression, pain-related anxiety, and pain-related acceptance; range significant $\Delta R^{2} .06-.09$ ). Final model Beta-weights for pain intensity, however, were significant for only physical disability and pain-related anxiety. 
In step 2, pain-related distress accounted for significant additional variance for all measures, with the exception of pain management coping (range significant $\Delta R^{2} .02-.19$ ). In each case where significant additional variance was indicated, final model Beta's were also significant.

The VT items, added in the final block, contributed further unique variance in eleven out of twelve measures (range significant $\Delta R^{2} .02-.17$ ). Physical disability was the only measure for which significant variance was not added by the VT items. The VT items accounted for the most unique variance in psychological flexibility coping $\left(\Delta R^{2}=.17\right)$ and values success $\left(\Delta R^{2}=.11\right)$ and the least unique variance in levels of physical and psychosocial disability $\left(\Delta R^{2}=.01\right.$ and .02 , respectively). These results suggest that the VT items captured additional information related to patient functioning in those with chronic pain. In each case where significant additional variance was added, the final model Beta's were significant.

\section{Supplementary Analyses}

Supplementary Tables 1 and 2 display results of the regression analysis with the CPVI subscales entered in the third step and the VT in the final step. Across these analyses, the VT accounted for significant variance above and beyond the CPVI scales in 14 of 18 analyses. When a significant increase in variance accounted for was indicated, average change in $\mathrm{R}^{2}=.06(S D=$ .04). Significant final model Beta-weights were indicated in each case where a significant increase in variance was indicated. A non-significant increase in variance was found for physical disability, psychosocial disability, and depression after controlling for values success (Supplementary Table 1) and for physical disability only for values discrepancy (Supplementary Table 2).

\section{Discussion}


The present study employed a series of hierarchical regression analyses to examine the relations among the two-items of the VT and aspects of patient functioning. An overarching aim of the analyses was to examine whether this concise instrument could account for significant variance in important measures of patient functioning, beyond that which could be accounted for by pain intensity and pain-related distress alone. Overall, the VT items accounted for a significant amount of variance in relevant measures of functioning, beyond that which could be accounted for by pain intensity and pain-related distress. This suggests that tracking behaviors related to the pursuit of values may have meaningful treatment implications in chronic pain rehabilitation settings. Furthermore, the overall pattern of results is consistent with the theory underlying ACT. In particular, the analyses in the present study demonstrated robust findings related to ACT-relevant constructs, such as pain-related acceptance, values success, and selfcompassion, as well as psychological flexibility coping, which are all facets of the behavioral repertoire that is emphasized within the ACT model.

It is important to note from a theoretical standpoint that values-based action is not necessarily associated with pain intensity or distress in the context of chronic pain. Simply put, there is an assumption that engagement in valued activity is possible while experiencing pain and distress. Support for this assumption comes from the correlation patterns within the present results, where the VT items were not correlated with pain-intensity and only weakly correlated with pain distress, while these same two items were reasonably well correlated across the various aspects of patient functioning that were assessed. Put in another way, engagement with values is not assumed to be contingent upon how someone feels or levels of pain-related functioning. Indeed, the ACT model involves confronting the patterns of avoidance that are common among those who suffer from chronic pain, which may involve feelings of discomfort in the short term. 
Because of the close relation between the subscales of the CPVI, which assess overall success in valued activities and the discrepancy between valued activity importance and valued activity success, and the items of the VT, we also analyzed whether the latter accounted for significant variance in aspects of functioning after controlling for the subscales of the CPVI. Overall, the results of these analyses indicated that the two items of the VT continued to account for significant variance after controlling for the CPVI subscales. While the magnitude of variance accounted for was modest in many cases, it would seem that the VT provided discrete utility in the statistical prediction of functioning in this sample of patients. The overall intention of the VT is to provide a brief summary of progress in valued areas over the preceding week, a format that ideally is formatted for repeated measurement over time, for example, as a weekly measure of progress in this area during treatment. While the present study is composed entirely of cross-sectional data, the fact that the VT held up fairly well after accounting for the variance of the slightly longer (12 item) CPVI, a measure which has evidence of psychometric and clinic utility, is promising.

The present study provides for interesting avenues for future research that involve using the VT in clinical practice for further evaluation. Ultimately, the VT should be evaluated in a longitudinal design, where patterns of values-based activity over time can be examined in relation to outcomes in chronic pain rehabilitation and measurement of behavioral changes. In addition to providing empirical evidence on the clinical utility of the VT, longitudinal data can also assist with examining whether values are an important mechanism of change. Understanding the critical ingredients in a treatment aids in enhancing the science of behavior change, particularly in optimizing interventions such that facets that do not contribute to changes in functioning can be reworked or eliminated altogether. Evaluating the VT as a mechanism of 
change allows for an explicit evaluation of the ACT model as well, in which treatment success is judged against the successful engagement in freely chosen values.

The concise nature of the VT makes it highly amenable to utilization for daily assessment because its burden on patients is minimal and the data it provides is potentially valuable. Administration of this measure electronically would likely be advantageous by making it easier for patients to complete frequently and providing the opportunity to set up reminders to complete the measure, to increase compliance if needed. Electronic administration also allows for data collection in real time and eliminates the need for data entry.

Although the results provide confirmatory evidence pertaining to the relevance of values to ACT-based treatment and convergent validity of the VT, there are limitations to document. First, the present study is a preliminary effort and the cross-sectional nature of the research design limits interpretation of the findings. At present, it can be concluded that there are significant associations between the VT and multiple measures of patient functioning and that the VT accounts for variance in patient functioning above and beyond the variance accounted for by measures of pain intensity and pain-related distress. A longitudinal design is required to assess whether the VT is a causal mechanism in patient improvement by examining whether changes in VT scores (i.e. the slope) over time are a significant mediator in the relationship between baseline functioning and treatment outcome.

Interestingly, the VT was not highly related to measures of disability, specifically physical disability, and the VT did not account for addition variance in levels of physical disability above and beyond pain and distress. Typically, level of values engagement are closely related to level of physical disability. This may be a limitation of the brevity of this measure. 
Another limitation of the present study is the self-report nature of the VT, which only provides the respondents' perception of their change. A multi-method approach toward assessing the values items, such as via clinician report, spousal report, or both, may provide a broader, more comprehensive perspective on progress in values-based living and increase validity of the measure.

In summary, the results of the present study provide preliminary evidence in support of the utility and validity of the VT in chronic pain treatment settings. The VT demonstrated significant associations with measures of patient functioning above and beyond that accounted for by relevant covariates. Furthermore, the overall pattern of results was consistent with the underlying theory of ACT, providing preliminary evidence of convergent validity of the VT. This is an important step in evaluating the science of behavior change pertaining to ACT. Given the robust nature of this two-item measure, the results of the present study provide a foundation and justification for examining the VT longitudinally to determine if changes in VT responses over time relate to treatment outcomes. Overall, a key feature of the VT is its brevity and low respondent burden, which makes it ideal for generating an abundance of rich data through daily diary research. 
Conflict of Interest: There are no conflicts of interest to report with this study. 


\section{References}

American Psychiatric Association. (2000). Diagnostic and Statistical Manual of Mental Disorders (4th, text.). Washington, D.C.: Author.

American Psychological Association, Society of Clinical Psychology (2013). Acceptance and Committment Therapy for chronic pain. Accessed at: http://www.div12.org/psychologicaltreatments/treatments/acceptance-and-commitment-therapy-for-chronic-pain/

Andersson, H. I. (2004). The course of non-malignant chronic pain: a 12-year follow-up of a cohort from the general population. European Journal of Pain, 8, 47-53.

Bergner, M., Bobbitt, R. A., Carter, W. B., \& Gilson, B. S. (1981). The Sickness Impact Profile: development and final revision of a health status measure. Medical Care, 19, 787-805.

Breivik, H., Campbell, W. I., \& Nicholas, M. K. (2008). Clinical Pain Management: Practice and Procedures (2nd ed.). London: Hodder Arnold.

Breivik, H., Collett, B., Ventafridda, V., Cohen, R., \& Gallacher, D. (2006). Survey of chronic pain in Europe: prevalence, impact on daily life, and treatment. European Jounal of Pain, $10,287-333$.

Campbell, W. I., \& Vowles, K. E. (2008). Practical methods for pain intensity measurements. In A. Rice, H. Breivik, W. I. Campbell, \& M. K. Nicholas (Eds.), Clinical pain management: Practice and procedures (2nd ed., pp. 12-27). New York: Hodder Arnold.

Cohen, J., Cohen, P., West, S., \& Aiken, L. (2003). Applied multiple regression/ correlation analysis for the behavioral sciences (3rd ed.). New Jersey: Lawrence Erlbaum Associates.

Elliott, A. M., Smith, B. H., Hannaford, P. C., Smith, W. C., \& Chambers, W. A. (2002). The course of chronic pain in the community: Results of a 4-year follow-up study. Pain, 99, 299-307. 
Fordyce, W. E. (1976). Behavioral methods for chronic pain and illness. St Louis: C. V. Mosby. Gaskin, D., \& Richard, P. (2012). The economic costs of pain in the United States. The Journal of Pain, 13, 715-24.

Hayes, S., Strosahl, K., \& Wilson, K. (2012). Acceptance and committment therapy: The process and practice of mindful change (2nd ed.). New York: Guilford Press.

Iverson, G. L., \& Remick, R. (2004). Diagnostic accuracy of the British Columbia Major Depression Inventory. Psychological Reports, 95, 1241-1247.

Jensen, M. P., \& Karoly, P. (1992). Self-report scales and procedures for assessing pain in adults. In D. C. Turk \& R. Melzack (Eds.), Handbook of Pain Assessment (pp. 135-151). New York, NY: Guilford Press.

Jensen, M. P., Vowles, K. E., Johnson, L. E., \& Gertz, K. J. (n.d.). Living well with pain: Development and preliminary evaluation of the Valued Living Scale. Pain Medicine.

Main, C. J., Keefe, F. J., Jensen, M. P., Vlaeyen, J. W. S., \& Vowles, K. E. (Eds.). (2014). Fordyce's behavioral methods for chronic pain and illness. New York: Walters-Kluwer.

McCracken, L. M. (2005). Contextual cognitive-behavioral therapy for chronic pain. Seattle, WA: IASP Press.

McCracken, L. M., \& Dhingra, L. (2002). A short version of the Pain Anxiety Symptoms Scale (PASS-20): Preliminary development and validity. Pain Research and Management, 7, 4550.

McCracken, L. M., \& Vowles, K. E. (2007). Psychological flexibility and traditional pain management strategies in relation to patient functioning with chronic pain: an examination of a revised instrument. Journal of Pain, 8, 700-707. 
McCracken, L. M., \& Vowles, K. E. (2008). A prospective analysis of acceptance of pain and values-based action in patients with chronic pain. Health Psychology, 27, 215-220.

McCracken, L. M., \& Vowles, K. E. (2014). Acceptance and Commitment Therapy and mindfulness for chronic pain: Model, process, and progress. American Psychologist, 69, $178-187$.

McCracken, L. M., Vowles, K. E., \& Eccleston, C. (2004). Acceptance of chronic pain: component analysis and a revised assessment method. Pain, 107, 159-166.

McCracken, L. M., \& Yang, S. (2006). The role of values in a contextual cognitive-behavioral approach to chronic pain. Pain, 123, 137-145.

Neff, K. D. (2003). The development and validation of a scale to measure self-compassion. Self and Identity, 2, 223-250.

Reneman, M. F., Dijkstra, A., Geertzen, J. H. B., \& Dijkstra, P. U. (2010). Psychometric properties of Chronic Pain Acceptance Questionnaires: a systematic review. European Jounal of Pain, 14, 457-565.

Roelofs, J., McCracken, L., Peters, M. L., Crombez, G., van Breukelen, G., \& Vlaeyen, J. W. (2004). Psychometric evaluation of the Pain Anxiety Symptoms Scale (PASS) in chronic pain patients. Journal of Behavioral Medicine, 27, 167-183.

Smith, B. H., Elliott, A. M., Chambers, W. A., Smith, W. C., Hannaford, P. C., \& Penny, K. (2001). The impact of chronic pain in the community. Family Practice, 18, 292-299.

Vowles, K. E., Fink, B., \& Cohen, L. (2014). Acceptance and Commitment Therapy for chronic pain: A diary study of treatment process in relation to reliable change in disability. Journal of Contextual Behavioral Science, 3, 74-80. 
Vowles, K. E., Gross, R. T., \& McCracken, L. M. (2007). Evaluating outcomes in the interdisciplinary treatment of chronic pain: A guide for practicing clinicians. In M. Schatman \& A. Campbell (Eds.), Chronic Pain Management: Guidelines for Multidisciplinary Program Development (pp. 203-220). New York: Informa.

Vowles, K. E., \& McCracken, L. M. (2008). Acceptance and values-based action in chronic pain: a study of treatment effectiveness and process. Journal of Consulting and Clinical Psychology, 76(3), 397-407.

Vowles, K. E., \& McCracken, L. M. (2010). Comparing the role of psychological flexibility and traditional pain management coping strategies in chronic pain treatment outcomes. Behaviour Research and Therapy, 48, 141-146.

Vowles, K. E., McCracken, L. M., McLeod, C., \& Eccleston, C. (2008). The Chronic Pain Acceptance Questionnaire: Confirmatory factor analysis and identification of patient subgroups. Pain, 140, 284-291.

Vowles, K. E., McCracken, L. M., \& O’Brien, J. Z. (2011). Acceptance and values-based action in chronic pain: a three-year follow-up analysis of treatment effectiveness and process. Behaviour Research and Therapy, 49, 748-755.

Vowles, K. E., McCracken, L. M., Sowden, G., \& Ashworth, J. (2014). Psychological flexibility in coping with chronic pain: Further examination of the Brief Pain Coping Inventory-2. Clinical Journal of Pain, 30, 324-330.

Vowles, K. E., Sowden, G., \& Ashworth, J. (2014). A comprehensive examination of the model underlying Acceptance and Commitment Therapy for chronic pain. Behavior Therapy, 45, 390-401. 
Vowles, K. E., \& Thompson, M. (2011). Acceptance and Commitment Therapy for chronic pain. In L. M. McCracken (Ed.), Mindfulness and acceptance in behavioral medicine: Current theory and practice (pp. 31-60). Oakland, CA: New Harbinger Publications.

Vowles, K. E., Witkiewitz, K., Sowden, G., \& Ashworth, J. (2014). Acceptance and Commitment Therapy for chronic pain: Evidence of mediation and clinically significant change following an abbreviated interdisciplinary program of rehabilitation. Journal of Pain, 15, 101-113.

Vowles, K. E., Zvolensky, M. J., Gross, R. T., \& Sperry, J. A. (2004). Pain-related anxiety in the prediction of chronic low-back pain distress. Journal of Behavioral Medicine, 27, 77-89.

Wicksell, R. K., Olsson, G. L., \& Melin, L. (2009). The Chronic Pain Acceptance Questionnaire (CPAQ)-further validation including a confirmatory factor analysis and a comparison with the Tampa Scale of Kinesiophobia. European Jounal of Pain, 13, 760-768.

doi:10.1016/j.ejpain.2008.09.003 
Table 1. Correlations and Descriptive Characteristics among the Values Tracker, Pain Variables, and Measures of Patient Functioning

\begin{tabular}{|c|c|c|c|c|c|}
\hline Functional Measure & $\begin{array}{l}\text { Values } \\
\text { Tracker }\end{array}$ & $\begin{array}{c}\text { Pain } \\
\text { Intensity }\end{array}$ & Distress & M & $S D$ \\
\hline Values Tracker & -- & -.07 & $-.14 \dagger$ & 9.7 & 4.9 \\
\hline Pain Intensity & & -- & $.55 * *$ & 7.3 & 1.7 \\
\hline Distress & & & -- & 6.5 & 2.7 \\
\hline \multicolumn{6}{|l|}{ Pain-related functioning } \\
\hline Physical disability & $-.13 \dagger$ & $.29 * *$ & $.33 * *$ & .21 & .14 \\
\hline Psychosocial disability & $-.18^{*}$ & $.25^{* *}$ & $.42 * *$ & .27 & .17 \\
\hline Independence/other disability & $-.26 * *$ & $.28 * *$ & $.36^{* *}$ & .27 & .11 \\
\hline Depression & $-.28 * *$ & $.27 * *$ & $.51 * *$ & 30.6 & 14.7 \\
\hline Pain-related anxiety & $-.18^{*}$ & $.30 * *$ & $.38 * *$ & 48.4 & 21.8 \\
\hline \multicolumn{6}{|l|}{ ACT constructs } \\
\hline Pain acceptance & $.32 * *$ & $-.30 * *$ & $-.44 * *$ & 50.6 & 17.8 \\
\hline Values success & $.41^{* *}$ & -.12 & $-.33 * *$ & 2.09 & 1.12 \\
\hline Values discrepancy & $.22 * *$ & -.11 & $-.30 * *$ & -1.7 & 1.01 \\
\hline Self-compassion & $.33 * *$ & -.11 & $-.41 * *$ & 68.5 & 17.6 \\
\hline \multicolumn{6}{|l|}{ Pain coping behaviors } \\
\hline Psychological flexibility coping & $.44 * *$ & -.11 & $-.33 * *$ & 38.3 & 13.8 \\
\hline Traditional pain management coping & $.34 * *$ & -.004 & -.10 & 25.8 & 12.6 \\
\hline
\end{tabular}

NOTE: Disability (Physical, Psychosocial, Independence/Other) was assessed via the Sickness Impact Profile; Depression via the British Columbia Major Depression Inventory, Pain-related anxiety via the Pain Anxiety Symptoms Scale, Pain acceptance via the Chronic Pain Acceptance Questionnaire, Values success and discrepancy via the Chronic Pain Values Inventory, Selfcompassion via the Self-Compassion Scale, and Pain coping behaviors via the Brief Pain Coping Inventory-2 
Table 2. Hierarchical Regression Analyses Examining Unique Contributions of Values Tracker Data to Measures of Patient Functioning after Controlling for Pain Intensity and Distress

\begin{tabular}{|c|c|c|c|}
\hline Step and Predictor(s) & Beta (final) & $\Delta \mathrm{R}^{2}$ & Total $\mathrm{R}^{2}$ \\
\hline \multicolumn{4}{|l|}{ Pain-related functioning } \\
\hline \multicolumn{4}{|l|}{ Physical disability } \\
\hline 1. Pain Duration & $.16 \dagger$ & $.02 \dagger$ & \\
\hline 2. Pain intensity & $.16 \dagger$ & $.08 * *$ & \\
\hline 3. Distress & $.22 *$ & $.04 * *$ & \\
\hline 4. Values Tracker & -.09 & .01 & .15 \\
\hline \multicolumn{4}{|l|}{ Psychosocial disability } \\
\hline 1. Pain intensity & .01 & $.04 * *$ & \\
\hline 2. Distress & $.39 * *$ & $.12 * *$ & \\
\hline 3. Values Tracker & $-.12 \dagger$ & $.02 \dagger$ & .18 \\
\hline \multicolumn{4}{|c|}{ Independence/other disability } \\
\hline 1. Pain intensity & .10 & $.07 * *$ & \\
\hline 2. Distress & $.27 * *$ & $.06^{* *}$ & \\
\hline 3. Values Tracker & $-.21 * *$ & $.05 * *$ & .18 \\
\hline \multicolumn{4}{|l|}{ Depression } \\
\hline 1. Pain intensity & -.02 & $.07 * *$ & \\
\hline 2. Distress & $.49 * *$ & $.19 * *$ & \\
\hline 3. Values Tracker & $-.18 *$ & $.03 *$ & .29 \\
\hline \multicolumn{4}{|l|}{ Pain-related anxiety } \\
\hline 1. Pain Duration & $.15 \dagger$ & $.02 \dagger$ & \\
\hline 2. Pain intensity & $.15 \dagger$ & $.09 * *$ & \\
\hline 3. Distress & $.30 * *$ & $.08 * *$ & \\
\hline 4. Values Tracker & $-.13 \dagger$ & $.02 \dagger$ & .21 \\
\hline \multicolumn{4}{|l|}{ ACT Constructs } \\
\hline \multicolumn{4}{|l|}{ Pain acceptance } \\
\hline 1. Pain intensity & -.07 & $.08 * *$ & \\
\hline 2. Distress & $-.35 * *$ & $.11 * *$ & \\
\hline 3. Values Tracker & $.24 * *$ & $.06 * *$ & .25 \\
\hline \multicolumn{4}{|l|}{ Values success } \\
\hline 1. Pain intensity & .07 & .01 & \\
\hline 2. Distress & $-.30 * *$ & $.11^{* *}$ & \\
\hline 3. Values Tracker & $.34 * *$ & $.11 * *$ & .23 \\
\hline
\end{tabular}


Table 2 (con't)

\begin{tabular}{|c|c|c|c|}
\hline Step and Predictor(s) & Beta (final) & $\Delta \mathrm{R}^{2}$ & Total $\mathrm{R}^{2}$ \\
\hline \multicolumn{4}{|c|}{ Discrepancy between values importance \& } \\
\hline success & .10 & .01 & \multirow{4}{*}{.11} \\
\hline 1. Pain intensity & $-.31 * *$ & $.08 * *$ & \\
\hline 2. Distress & $.16 \dagger$ & $.02 \dagger$ & \\
\hline 3. Values Tracker & & & \\
\hline \multicolumn{4}{|l|}{ Self-compassion } \\
\hline 1. Pain intensity & .13 & .01 & \multirow[b]{3}{*}{.27} \\
\hline 2. Distress & $-.45 * *$ & $.17 * *$ & \\
\hline 3. Values Tracker & $.29 * *$ & $.09 * *$ & \\
\hline \multicolumn{4}{|l|}{ Pain coping behaviors } \\
\hline \multicolumn{4}{|c|}{ Psychological flexibility coping } \\
\hline 1. Pain intensity & .02 & .01 & \multirow[b]{3}{*}{.28} \\
\hline 4. Distress & $-.32 * *$ & $.10 * *$ & \\
\hline 5. Values Tracker & $.41 * *$ & $.17 * *$ & \\
\hline \multicolumn{4}{|c|}{ Traditional pain management coping } \\
\hline 1. Pain intensity & .06 & $<.001$ & \\
\hline 2. Distress & -.10 & .02 & \\
\hline 3. Values Tracker & $.32 * *$ & $.10 * *$ & .12 \\
\hline
\end{tabular}

NOTE: Disability (Physical, Psychosocial, Independence/Other) was assessed via the Sickness Impact Profile; Depression via the British Columbia Major Depression Inventory, Pain-related anxiety via the Pain Anxiety Symptoms Scale, Pain acceptance via the Chronic Pain Acceptance Questionnaire, Values success and discrepancy via the Chronic Pain Values Inventory, Selfcompassion via the Self-Compassion Scale, and Pain coping behaviors via the Brief Pain Coping Inventory-2. 
Supplementary Table 1. Hierarchical Regression Analyses Examining Unique Contributions of Values Tracker Data to Measures of Patient Functioning after Controlling for Pain Intensity, Distress, and Values Success.

\begin{tabular}{|c|c|c|c|}
\hline Step and Predictor(s) & Beta (final) & $\Delta \mathrm{R}^{2}$ & Total $\mathrm{R}^{2}$ \\
\hline \multicolumn{4}{|l|}{ Pain-related functioning } \\
\hline \multicolumn{4}{|l|}{ Physical disability } \\
\hline 1. Pain Duration & $.16 \dagger$ & $.02 \dagger$ & \\
\hline 2. Pain intensity & $.19^{*}$ & $.08 * *$ & \\
\hline 3. Distress & .10 & $.04 *$ & \\
\hline 4. Values Success & $-.28 * *$ & $.07 * *$ & \\
\hline 5. Values Tracker & -.01 & $<.001$ & .21 \\
\hline \multicolumn{4}{|l|}{ Psychosocial disability } \\
\hline 1. Pain intensity & .04 & $.04 * *$ & \\
\hline 2. Distress & $.29 * *$ & $.12 * *$ & \\
\hline 3. Values Success & $-.34 * *$ & $.11 * *$ & \\
\hline 4. Values Tracker & -.05 & $<.001$ & .27 \\
\hline \multicolumn{4}{|c|}{ Independence/other disability } \\
\hline 1. Pain intensity & $.15 \dagger$ & $.07 * *$ & \\
\hline 2. Distress & $.15 \dagger$ & $.06^{* *}$ & \\
\hline 3. Values Success & $-.34 * *$ & $.14 * *$ & \\
\hline 4. Values Tracker & -.05 & $.02 *$ & .29 \\
\hline \multicolumn{4}{|l|}{ Depression } \\
\hline 1. Pain intensity & -.03 & $.07 * *$ & \\
\hline 2. Distress & $.38 * *$ & $.19 * *$ & \\
\hline 3. Values Success & $-.39 * *$ & $.16^{* *}$ & \\
\hline 4. Values Tracker & -.09 & .01 & .44 \\
\hline \multicolumn{4}{|l|}{ Pain-related anxiety } \\
\hline 1. Pain Duration & $.19^{*}$ & $.02 \dagger$ & \\
\hline 2. Pain intensity & $.18^{*}$ & $.09 * *$ & \\
\hline 3. Distress & $.20 *$ & $.08 * *$ & \\
\hline 4. Values Success & -.13 & $.03 *$ & \\
\hline 5. Values Tracker & $-.12 \dagger$ & $.01 \dagger$ & .23 \\
\hline \multicolumn{4}{|l|}{ ACT Constructs } \\
\hline \multicolumn{4}{|l|}{ Pain acceptance } \\
\hline 1. Pain intensity & $-.17^{*}$ & $.08 * *$ & \\
\hline 2. Distress & $-.18 *$ & $.11 * *$ & \\
\hline 3. Values Success & $.35 * *$ & $.15^{* *}$ & \\
\hline 4. Values Tracker & $.20^{*}$ & $.03 * *$ & .37 \\
\hline
\end{tabular}

$* * p<.001, * p<.01, \dagger p<.05$ (table continues) 
Supplementary Table 1 (con’t)

\begin{tabular}{|c|c|c|c|}
\hline Step and Predictor(s) & Beta (final) & $\Delta \mathrm{R}^{2}$ & Total $\mathrm{R}^{2}$ \\
\hline \multicolumn{4}{|l|}{ Self-compassion } \\
\hline 1. Pain intensity & .12 & .01 & \\
\hline 2. Distress & $-.37 * *$ & $.08 * *$ & \\
\hline 3. Values Success & $.25^{*}$ & $.11 * *$ & \\
\hline 4. Values Tracker & $.31 * *$ & $.09 * *$ & .38 \\
\hline \multicolumn{4}{|l|}{ Pain coping behaviors } \\
\hline \multicolumn{4}{|c|}{ Psychological flexibility coping } \\
\hline 1. Pain intensity & -.01 & .01 & \\
\hline 2. Distress & $-.28 *$ & $.10 * *$ & \\
\hline 3. Values Success & $.24^{*}$ & $.12 * *$ & \\
\hline 4. Values Tracker & $.33^{* *}$ & $.09 * *$ & .32 \\
\hline \multicolumn{4}{|c|}{ Traditional pain management coping } \\
\hline 1. Pain intensity & .02 & $<.001$ & \\
\hline 2. Distress & -.09 & .02 & \\
\hline 3. Values Success & .02 & .01 & \\
\hline 4. Values Tracker & $.30 * *$ & $.09 * *$ & .13 \\
\hline
\end{tabular}

NOTE: Disability (Physical, Psychosocial, Independence/Other) was assessed via the Sickness Impact Profile; Depression via the British Columbia Major Depression Inventory, Pain-related anxiety via the Pain Anxiety Symptoms Scale, Pain acceptance via the Chronic Pain Acceptance Questionnaire, Self-compassion via the Self-Compassion Scale, and Pain coping behaviors via the Brief Pain Coping Inventory-2. 
Supplementary Table 2. Hierarchical Regression Analyses Examining Unique Contributions of Values Tracker Data to Measures of Patient Functioning after Controlling for Pain Intensity, Distress, and Values Discrepancy

\begin{tabular}{|c|c|c|c|}
\hline Step and Predictor(s) & Beta (final) & $\Delta \mathrm{R}^{2}$ & Total $\mathrm{R}^{2}$ \\
\hline \multicolumn{4}{|l|}{ Pain-related functioning } \\
\hline \multicolumn{4}{|l|}{ Physical disability } \\
\hline 1. Pain Duration & $.16 \dagger$ & $.02 \dagger$ & \\
\hline 2. Pain intensity & $.17 \dagger$ & $.08 * *$ & \\
\hline 3. Distress & .15 & $.04 *$ & \\
\hline 4. Values Discrepancy & $-.21 * *$ & $.05^{* *}$ & \\
\hline 5. Values Tracker & -.09 & .01 & .20 \\
\hline \multicolumn{4}{|l|}{ Psychosocial disability } \\
\hline 1. Pain intensity & .02 & $.04 * *$ & \\
\hline 2. Distress & $.31 * *$ & $.12 * *$ & \\
\hline 3. Values Discrepancy & $-.28 * *$ & $.08 * *$ & \\
\hline 4. Values Tracker & $-.13 \dagger$ & $.02 \dagger$ & .26 \\
\hline \multicolumn{4}{|c|}{ Independence/other disability } \\
\hline 1. Pain intensity & $.14 \uparrow$ & $.07 * *$ & \\
\hline 2. Distress & $.18^{*}$ & $.06^{* *}$ & \\
\hline 3. Values Discrepancy & $-.25 * *$ & $.07 * *$ & \\
\hline 4. Values Tracker & $-.23 * *$ & $.05^{* *}$ & .25 \\
\hline \multicolumn{4}{|l|}{ Depression } \\
\hline 1. Pain intensity & -.02 & $.07 * *$ & \\
\hline 2. Distress & $.40 * *$ & $.19 * *$ & \\
\hline 3. Values Discrepancy & $-.30 * *$ & $.10 * *$ & \\
\hline 4. Values Tracker & $-.19 * *$ & $.03 * *$ & .39 \\
\hline \multicolumn{4}{|l|}{ Pain-related anxiety } \\
\hline 1. Pain Duration & $.19^{*}$ & $.02 \dagger$ & \\
\hline 2. Pain intensity & $.18^{*}$ & $.09 * *$ & \\
\hline 3. Distress & $.20 *$ & $.08 * *$ & \\
\hline 4. Values Discrepancy & -.10 & .01 & \\
\hline 5. Values Tracker & $-.16^{*}$ & $.02 *$ & .22 \\
\hline \multicolumn{4}{|l|}{ ACT Constructs } \\
\hline \multicolumn{4}{|l|}{ Pain acceptance } \\
\hline 1. Pain intensity & $-.16 \dagger$ & $.08 * *$ & \\
\hline 2. Distress & $-.21 *$ & $.11 * *$ & \\
\hline 3. Values Discrepancy & $.26 * *$ & $.08 * *$ & \\
\hline 4. Values Tracker & $.27 * *$ & $.07 * *$ & .34 \\
\hline
\end{tabular}

$* * p<.001, * p<.01, \dagger p<.05$ (table continues) 
Supplementary Table 2 (con't)

\begin{tabular}{llll}
\hline Step and Predictor(s) & Beta (final) & $\Delta \mathrm{R}^{2}$ & Total $\mathrm{R}^{2}$ \\
\hline Self-compassion & & & \\
1. Pain intensity & .10 & .01 & \\
2. Distress & $-.35^{* *}$ & $.08^{* *}$ & \\
3. Values Discrepancy & $.17 \dagger$ & $.04 \dagger$ & \\
4. Values Tracker & $.36^{* *}$ & $.13^{* *}$ & .26 \\
Pain coping behaviors & & & \\
Psychological flexibility coping & & & \\
1. Pain intensity & -.03 & .01 & \\
2. Distress & $-.27^{*}$ & $.10^{* *}$ & \\
3. Values Discrepancy & $.17 \dagger$ & $.04 \dagger$ & \\
4. Values Tracker & $.38^{* *}$ & $.15^{* *}$ & .30 \\
Traditional pain management coping & & & \\
1. Pain intensity & & & \\
2. Distress & .03 & & \\
3. Values Discrepancy & -.10 & .001 & \\
4. Values Tracker & .01 & $<.001$ & \\
& $.31^{* *}$ & $.09^{* *}$ & .11 \\
\hline$* * p<.001, * p<.01, \dagger p<.05$ & & &
\end{tabular}

NOTE: Disability (Physical, Psychosocial, Independence/Other) was assessed via the Sickness Impact Profile; Depression via the British Columbia Major Depression Inventory, Pain-related anxiety via the Pain Anxiety Symptoms Scale, Pain acceptance via the Chronic Pain Acceptance Questionnaire, Self-compassion via the Self-Compassion Scale, and Pain coping behaviors via the Brief Pain Coping Inventory-2. 